\author{
Alexandre Fortier \\ Library of Parliament, Ottawa, Ontario, Canada \\ Heather J. Pretty \\ Memorial University of Newfoundland, St. John's, Newfoundland and Labrador, Canada \\ Daniel B. Scott \\ Laurentian University, Sudbury, Ontario, Canada \\ McGill University, Montreal, Quebec, Canada \\ Olivier Spéciel \\ Services Documentaires Multimédia Inc., Montreal, Quebec, Canada
}

\title{
ARE CANADIAN LIBRARIES READY TO TRANSITION FROM MARC TO BIBFRAME? (Paper)
}

\begin{abstract}
This project seeks to assess the Canadian library community's understanding of and readiness for the transition from the MARC format to the BIBFRAME model. Results indicate that knowledge of BIBFRAME is low among respondents and that most of the libraries surveyed do not know enough about BIBFRAME to consider planning a transition.

Résumé

Ce projet évalue la compréhension et l'état de préparation de la transition du format MARC au modèle BIBFRAME dans les bibliothèques canadiennes. Les résultats indiquent que les répondants connaissent peu le modèle BIBFRAME et que la majorité des bibliothèques interrogées ne sont pas prêtes à planifier la transition.
\end{abstract}

\section{Introduction}

Most libraries rely on the 1960s-era MARC format to describe items in their online catalogues, but the MARC format - a record-based format composed largely of string literals — is not well understood outside of the library community. To make library data more broadly useful and replace the MARC format (Morris 2019), the Library of Congress (LC) and international library community developed the Bibliographic Framework (BIBFRAME) linked data vocabulary (Park, Brenza and Richards 2020). Linked data uses Uniform Resource Identifiers (URIs, similar to web links) to unambiguously identify entities and relationships between entities and has been adopted by many different types of organizations (Fayyaz, Ullah and Khusro 2018). Canadian libraries rely on LC for leadership in cataloguing standards and as a source of freely available cataloguing data, so LC's transition from MARC to BIBFRAME will affect the infrastructure and staffing costs of libraries across Canada.

The transition from MARC to BIBFRAME will likely be similar in scope to libraries' transition from card catalogues to computer catalogues. Libraries will need to develop or build systems that can create and search BIBFRAME linked data, library staff will need training to understand how 
to describe items with the BIBFRAME vocabulary, and workflows will need to be adjusted accordingly. Linked data offers benefits that make the investment worthwhile: open standards for storing and querying linked data; links to other datasets such as Wikidata that provide additional data (including images and audio) that can enrich descriptions of items with contextual information about authors, subjects, and events; and of particular interest in the context of a multilingual country such as Canada, the ability for each link to offer labels in multiple languages (Alemu, Stevens, Ross and Chandler 2012; Allison-Cassin and Scott 2018).

Due to both LC's intention to begin cataloguing only in BIBFRAME by the end of 2020, and to the expected benefits offered by catalogues built on linked data, this project answers the following question: how ready are Canadian libraries to transition to BIBFRAME?

\section{Methods}

We conducted an online survey in English and French using Qualtrics software to obtain a portrait of the Canadian library community at large. The questionnaire (Fortier, Pretty, Scott and Spéciel 2019) assessed the (1) respondent's understanding of BIBFRAME (2) their organization's readiness to transition to BIBFRAME and collected (3) demographic data about the respondent's library and their role within the library ${ }^{\mathrm{i}}$. To assess readiness, we adopted a psychometric assessment that measures organizational readiness for implementing change (Shea et al. 2014). This instrument includes a five-item scale about change commitment, a six-item scale about change efficacy, and nine items representing various aspects of how much value respondents would place on a change.

We selected survey participants from a list of 5,812 Canadian libraries compiled from libraries.org (Breeding 2019) and Library and Archives Canada's (2019) interlibrary loan database. We then clustered the libraries into four mutually exclusive categories: academic libraries (6\%), public libraries (36\%), school libraries (14\%) and special libraries (44\%). Using these categories, we generated a stratified random sample of 1,500 libraries. After two pilot phases, we launched the survey on 14 November 2019 by sending emails with a link to answer the study in English or French targeting "the person most directly responsible for cataloguing" and "the person most directly responsible for systems". To replace emails that failed to be delivered, we sent invitations to another 125 libraries. We sent two reminders before the survey closed on 31 December 2019 and received 289 completed questionnaires. We rejected two responses that did not come from a Canadian library, resulting in a total of 287 analysed questionnaires. While this response rate (19\%) is not optimal, it is in line with studies using online surveys ${ }^{\mathrm{ii}}$ and allows us to draw an inclusive portrait of the Canadian library community.

\section{Results}

Questionnaires were returned from institutions located in ten provinces and one territory. 53\% reported having a catalogue in English only; 29\%, a catalogue in French only; and 17\%, a multilingual catalogue. The proportion of public libraries $(36 \%)$ follows their weight in the sample while academic libraries (16\%) are over-represented, and special libraries (37\%) and school 
libraries $(9 \%)$ are underrepresented. The majority of libraries $(65 \%)$ surveyed employ 1 to 5 librarians while $19 \%$ employ none. The majority of libraries (57\%) report having 1 to 5 staff members. The participants' primary responsibilities within the library vary greatly, the three most common being administration (22\%), cataloguing and metadata $(19 \%)$ and "all of the above" (17\%). A finer analysis of the answers indicates that $38 \%$ have "cataloguing responsibilities". Nearly three quarters of the participants (74\%) are responsible for training other employees while $46 \%$ have other employees reporting to them.

\subsection{Awareness of BIBFRAME}

The results first indicate that only $30 \%$ of respondents were aware of BIBFRAME as a replacement for the MARC bibliographic format prior to the survey. This proportion is higher for academic libraries (69\%), and lower for public libraries (28\%), special libraries (19\%) and school libraries $\left(19 \% ; \chi^{2}(4, N=286)=40.8, p<.001, V=.38\right.$; see Figure 1 below $)$. The proportion is also higher for libraries having more than 5 librarians $(6-10,57 \% ; 11-20,85 \%$; 21-50, 88\%; >50, $50 \% ; \chi^{2}(5, N=286)=47.91, p<.001, V=.41$; see Figure 2 below $)$ or more than 5 staff members $\left(6-10,31 \% ; 11-20,46 \% ; 21-50,52 \% ;>50,75 \% ; \chi^{2}(4, N=285)=50.14, p<.001, V=.42\right.$; see Figure 3 below). Of the $16 \%$ of respondents whose libraries report holdings to OCLC, $62 \%$ had heard about BIBFRAME prior to the survey $\left(\chi^{2}(2, N=286)=34.5, p<.001, V=.38\right)$. Respondents who indicated "cataloguing and metadata" (54\%), "systems" (39\%) or "technical services" (38\%) as their primary responsibility were also more likely to be aware of BIBFRAME in comparison to respondents who had other roles, including "all of the above" $\left(14 \% ; \chi^{2}(10, N=286)=28.34\right.$, $p=.002, V=.32$;).

Figure 1.

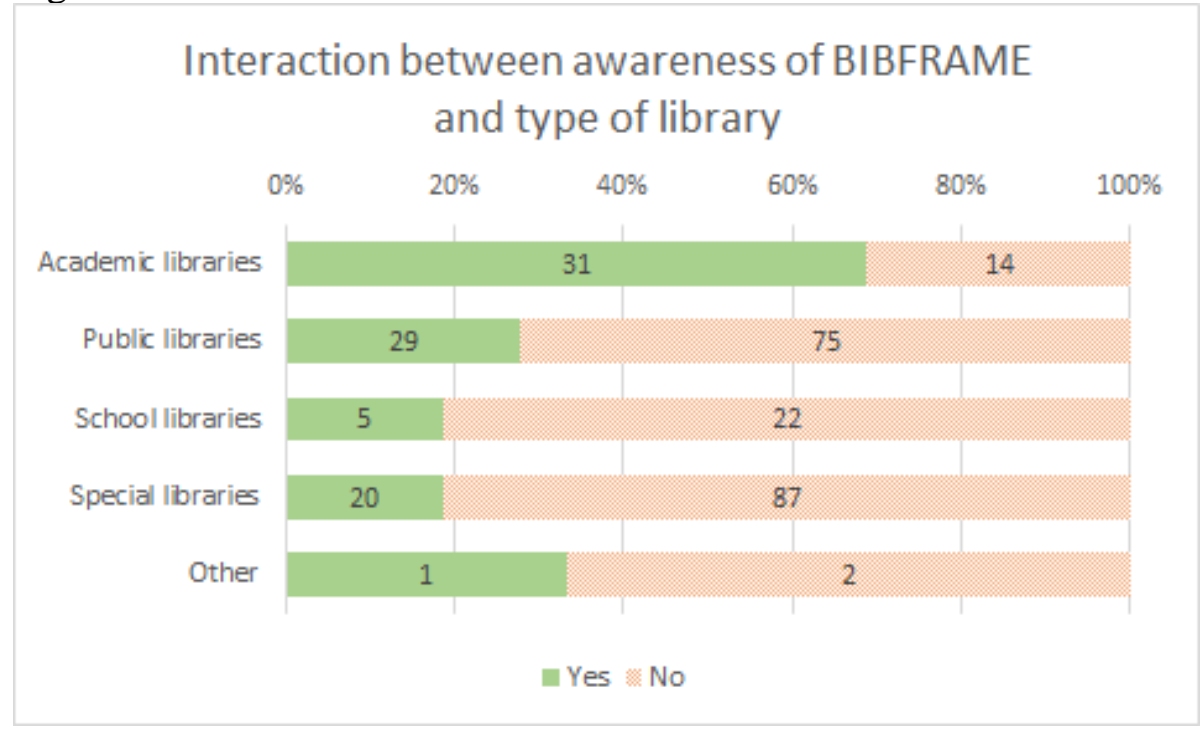


Figure 2.

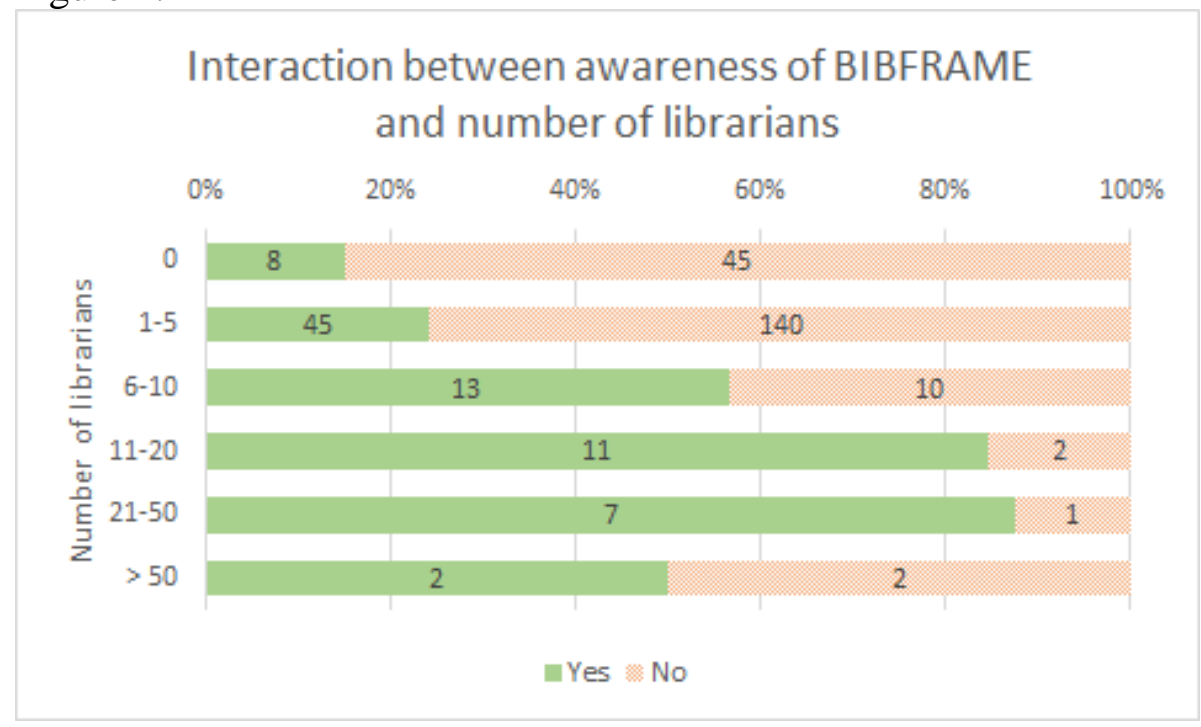

Figure 3.

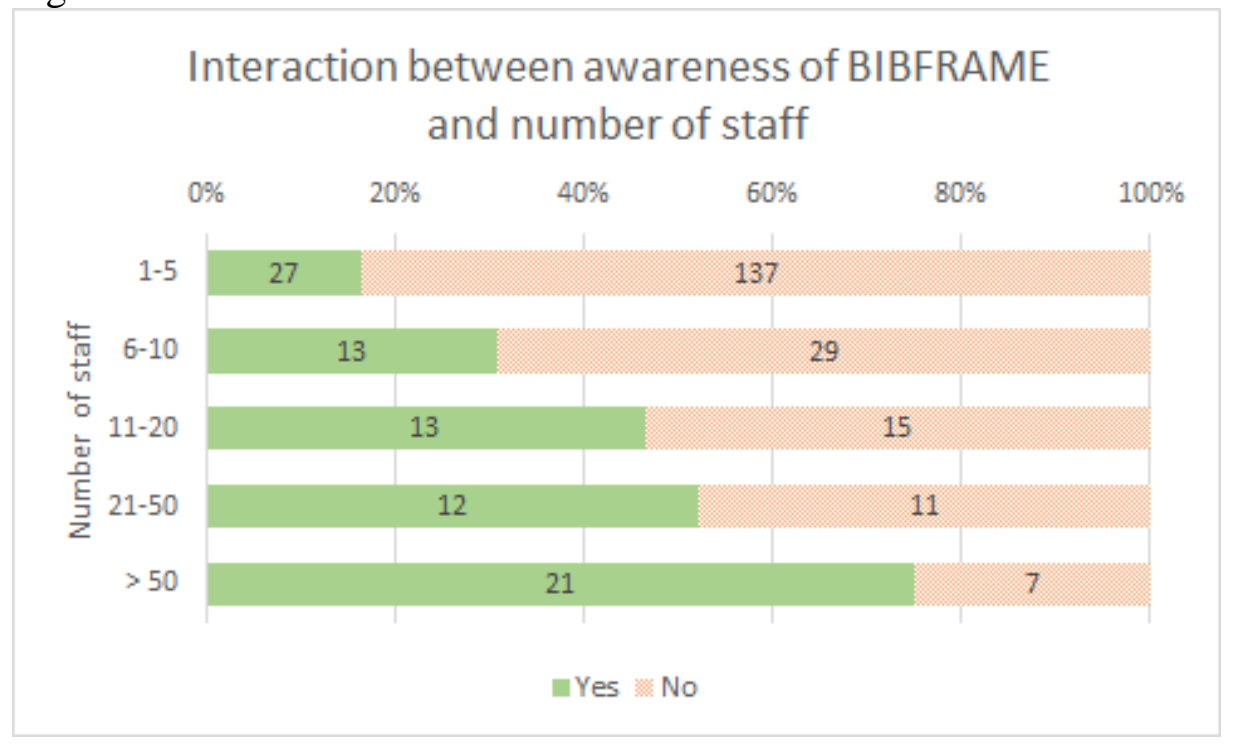

\subsection{Planned Transitions to BIBFRAME}

The results also indicate that $85 \%$ of the libraries surveyed do not yet know enough about BIBFRAME to consider planning a transition. This proportion is slightly lower for academic libraries $(82 \%)$, school libraries $(82 \%)$, and special libraries $(81 \%)$, and slightly higher for public libraries $\left(91 \% ; \chi^{2}(24, N=271)=45.5, p=.005, V=.21\right)$. For other variables measured, no specific trend can be observed. Only $1 \%$ of the libraries surveyed indicate that their transition from MARC to BIBFRAME is already underway. Among the libraries who are planning a transition, only $4 \%$ plan to transition within the next ten years, which mirrors the proportion of libraries (4\%) who plan to keep using MARC records and not transition to BIBFRAME. 


\subsection{Organization Readiness for BIBFRAME}

Respondents who indicated that they had heard of BIBFRAME prior to the survey $(n=87)$ were invited to answer questions regarding their readiness to transition to BIBFRAME and their understanding of BIBFRAME. Results indicate that, even for those who were aware of BIBFRAME, participants were neither committed nor opposed to transition. Results do not indicate interactions with any of the demographic variables. Participants were invited to rate their level of agreement with 5 items measuring their library's commitment to transition from MARC to BIBFRAME from 0 to 10 , and the average for this commitment score is 19 (out of 50). Participants were also invited to rate their level of agreement with 6 items measuring their library's ability to make the transition from 0 to 10 , and the average for this ability score is 26 (out of 60). Finally, they were asked to rate 9 items measuring different aspects of the perceived needs, benefits, and harms for their library to make the transition (such as cost-effectiveness and timeliness of the transition), and scores for individual items all have a median of 5 or 6 (out of 10).

\section{Conclusion}

In 2018, the Library of Congress announced that it would be migrating from MARC to BIBFRAME and the institution has now more than 100 cataloguers using BIBFRAME linked data format for original cataloguing instead of the MARC format (Canadian BIBFRAME Readiness Task Force 2019; Morris 2019). Data gathered for this study indicates that, across the Canadian library community at large, there was almost no awareness of BIBFRAME and that very few libraries appear to be ready to transition to BIBFRAME. While academic research projects about BIBFRAME are multiplying and major research libraries have also been preparing to adopt BIBFRAME (Kovari, Folsom and Younes 2017; Park, Richards and Brenza 2019; Samples and Bigelow 2020; Wennerlund and Berggren 2019) it remains to be seen how and when, in practice, libraries in general can follow them. As more libraries make the transition, it would be interesting to repeat this study to measure changes in readiness for transition to BIBFRAME. The academic community, through its training of future information professionals and its capacity to offer continuing education, has a role to play in fostering the understanding of linked data principles and supporting the transition of the Canadian library community to the BIBFRAME format.

\section{Reference List:}

Alemu, G., B. Stevens, P. Ross and J. Chandler. 2012. Linked data for libraries: Benefits of a conceptual shift from library-specific record structures to RDF-based data models. New Library World 113, no. 11/12: 549-570. https://doi.org/10.1108/03074801211282920

Allison-Cassin, S. and D. Scott. 2018. Wikidata: A platform for your library's linked open data. The Code4Lib Journal 40. https://journal.code4lib.org/articles/13424

Breeding, M. 2019. libraries.org: A directory of libraries throughout the world. https://librarytechnology.org/libraries/ 
Canadian BIBFRAME Readiness Task Force. 2019. A plain-language description of BIBFRAME and its potential impact on Canadian libraries.

http://cfla-fcab.ca/wp-content/uploads/2019/10/Final-Plain-Language-Description-of-BFelectronic.pdf

Fayyaz, N., I. Ullah and S. Khusro. 2018. On the current state of linked open data: Issues, challenges, and future directions. International Journal on Semantic Web and Information Systems 14, no. 4: 110-128. https://doi.org/10.4018/IJSWIS.2018100106

Fortier, A., H. J. Pretty, D. B. Scott and O. Spéciel. 2019. Canadian BIBFRAME Readiness Task Force survey instrument. https://zone.biblio.laurentian.ca/handle/10219/3551

Hardigan, P. C., I. Popovici and M. J. Carvajal. 2016. Response rate, response time, and economic costs of survey research: A randomized trial of practicing pharmacists. Research in Social and Administrative Pharmacy 12, no. 1: 141-148. https://doi.org/10.1016/j.sapharm.2015.07.003

Kovari, J., S. Folsom and R. Younes. 2017. Towards a BIBFRAME implementation: The bibliotek-o framework. Proceedings of the 2017 DCMI International Conference on Dublin Core and Metadata Applications, Washington, D.C., 26-29 October.

https://dcpapers.dublincore.org/pubs/article/view/3854

Library and Archives Canada. 2019. Symbols and Interlibrary Loan Policies in Canada. https://sigles-symbols.bac-lac.gc.ca/eng/Search

Morris, S. R. 2019. How does LC within BIBFRAME intend to accommodate RDA 3R? Paper presented at RDA: Resource Description and Access 2019, Thessaloniki, Greece, 21 August. https://www.loc.gov/bibframe/news/source/ifla2019-satellite-rda.pptx

Nulty, D. D. 2008. The adequacy of response rates to online and paper surveys: What can be done? Assessment \& Evaluation in Higher Education 33, no. 3: 301-314.

https://doi.org/10.1080/02602930701293231

Park, J., A. Brenza and L. Richards. 2020. Linked open data: Applications, trends and future developments. London: IntechOpen. https://doi.org/10.5772/intechopen.91849

Park, J., L. L. Richards and A. Brenza. 2019. Benefits and challenges of BIBFRAME: Cataloging special format materials, implementation, and continuing educational resources. Library Hi Tech 37, no. 3: 549-565. https://doi.org/10.1108/LHT-08-2017-0176

Samples, J. and I. Bigelow. 2020. MARC to BIBFRAME: Converting the PCC to linked data. Cataloging \& Classification Quarterly 58, no. 3/4: 403-417.

https://doi.org/10.1080/01639374.2020.1751764 
Shea, C. M., S. R. Jacobs, D. A. Esserman, K. Bruce and B. J. Weiner. 2014. Organizational readiness for implementing change: A psychometric assessment of a new measure. Implementation Science 9, no. 1. https://doi.org/10.1186/1748-5908-9-7

Ullah, I., S. Khusro, A. Ullah and M. Naeem. 2018. An overview of the current state of linked and open data in cataloging. Information Technology \& Libraries 37, no. 4: 47-80. https://doi.org/10.6017/ital.v37i4.10432

Wennerlund, B. and A. Berggren. 2019. Leaving comfort behind: A national union catalogue transition to linked data. Paper presented at the IFLA World Library Information Congress Satellite Meeting on "Data intelligence in libraries: the actual and artificial perspectives", Frankfurt, Germany, 22-23 August. http://library.ifla.org/2745/1/s15-2019-wennerlund-en.pdf

Yan, Z. and W. Fan. 2010. Factors affecting response rates of the web survey: A systematic review. Computers in Human Behaviors 26: 132-139. https://doi.org/10.1016/j.chb.2009.10.015

\footnotetext{
${ }^{\mathrm{i}}$ An analysis of the understanding of BIBFRAME is forthcoming.

${ }^{i i}$ See, for instance, Nulty (2008), Yan and Fan (2010) and Hardigan et al. (2016).
} 